\title{
Influence of Poisson's Ratio on the Stress vs. Settlement Behavior of Shallow Foundations in Unsaturated Fine-Grained Soils
}

\author{
W.T. Oh, S.K. Vanapalli
}

\begin{abstract}
Poisson's ratio is typically assumed to be constant for both saturated and unsaturated soils. However, the back-calculated Poisson's ratio using the relationship between elastic and shear modulus (i.e. the equation for homogeneous, isotropic and linear elastic continuum) published in the literature showed that the Poisson's ratio is not constant but decreases with the degree of saturation (or increasing suction). In the present study, more focused investigations are undertaken to study the influence of Poisson's ratio on the stress $v s$. settlement (SVS) behaviour of shallow foundations in an unsaturated fine-grained (UFG) soil. The FEA are carried out using the software, SIGMA/W (GeoStudio 2007) to better understand the SVS behavior taking account of the influence of Poisson's ratio for different matric suction values and compared with the model footing tests conducted in an UFG soil. Several suggestions are made with respect to the influence of Poisson's ratio on the SVS behavior of shallow foundations in the UFG soils based on the results of this study.
\end{abstract}

Keywords: unsaturated soil, poisson's ratio, stress $v s$. settlement, shallow foundation, finite element analysis.

\section{Introduction}

In recent years, significant advancements were made in the area of geotechnical engineering applications extending the mechanics of unsaturated soils for the shallow foundations (Ausilio \& Conte 1999, Costa et al., 2003, Cerato \& Lutenegger 2006, Oh \& Vanapalli 2013a), deep foundations (Weaver \& Grandi 2009, Vanapalli \& Taylan 2012), and heave analysis (Chao et al., 2001), etc.. However, laboratory or field studies on the unsaturated soils are timeconsuming, cumbersome, and require elaborate testing equipment. Due to this reason, more and more studies on the unsaturated soils are directed to Finite Element Analysis (hereafter referred to as FEA), which can be attributed to the recent advancements with respect to several semi-empirical or constitutive models for unsaturated soils (Georgiadis et al., 2003, Vu \& Fredlund 2006, Wejrungsikul et al., 2011, Oh \& Vanapalli 2011a,b, Adem \& Vanapalli 2013, Gallipoli et al., 2013). In the present study, an attempt is made to estimate the stress $v s$. settlement (hereafter referred to as SVS) behavior of a model footing (i.e. shallow foundation) in unsaturated fine-grained (hereafter referred to as UFG) soils using the FEA extending mechanics of unsaturated soils.

The bearing capacity and settlement are two key parameters in the design of shallow foundations. However, it is commonly acknowledged that the design of shallow foundations is typically governed by settlement behavior rather than the bearing capacity. Mohamed \& Vanapalli (2006) carried out model footing ( $B \times L=100 \mathrm{~mm} \times$ $100 \mathrm{~mm}$ and $150 \mathrm{~mm} \times 150 \mathrm{~mm}$ ) tests in a sandy soil for four different average matric suction values (i.e. 0, 2, 4 and $6 \mathrm{kPa}$ ). Based on their experimental results, Vanapalli \& Mohamed (2007) proposed a semi-empirical model to estimate the variation of bearing capacity of coarse-grained soils with respect to matric suction. However, the SVS behaviours from the model footing test results showed that the matric suction has significant influence on not only bearing capacity but also on the initial tangent elastic modulus, $E_{i}$. In other words, the reliable estimation of elastic settlement in unsaturated soils can be obtained by considering the variation of initial tangent elastic modulus with respect to matric suction. By extending this concept, Oh et al. (2009) proposed a semi-empirical model that can be used to estimate the variation of initial tangent elastic modulus with respect to matric suction for coarse-grained soils below shallow foundations. This model uses two fitting parameters, $\alpha$ and $\beta$ and the Soil-Water Characteristic Curve (hereafter referred to as SWCC). Vanapalli \& Oh (2010) extended this model to fine-grained soils with Plasticity Index, $I_{p}$ values less than $16 \%$ and showed that fitting parameter, $\alpha$ is a function of $I_{p}$. This model can be effectively used to estimate elastic settlement of unsaturated soils below shallow foundations; however, there is limitation to identify stress ranges corresponding to elastic settlement. To overcome this disadvantage, Oh \& Vanapalli (2011a) proposed two methods to predict the variation of the SVS behavior of shallow foundations located on the surface of coarsegrained soils. In the first method, the SVS behavior was idealized using two straight lines, which represent elastic and perfectly plastic behaviour, respectively. These two

Won Taek Oh, Ph.D., Department of Civil Engineering, University of New Brunswick, Fredericton, Canada. e-mail: woh@unb.ca.

Sai K. Vanapalli, Ph.D., Department of Civil Engineering, University of Ottawa, Ottawa, Ontario, Canada. e-mail: vanapall@eng.uottawa.ca.

Invited Article, no discussion. 
straight lines were established extending the concepts proposed by Oh et al. (2009) and Vanapalli \& Mohamed (2007) to predict the initial tangent modulus of subgrade reaction based on initial tangent elastic modulus and bearing capacity with respect to matric suction, respectively. In the second method, the FEA was carried out also using elastic perfectly plastic model with Mohr-Coulomb yield criterion (Chen \& Zhang 1991). In the FEA, the soil profile was assumed to be a single layer with average matric suction value (i.e. constant total and apparent cohesion and initial tangent elastic modulus). The second method (i.e. FEA) has been successfully used to simulate the SVS behavior of in-situ footing ( $B \times L=1 \mathrm{~m} \times 1 \mathrm{~m}$ ) load test results in unsaturated sand (Oh \& Vanapalli 2011b, 2012). The studies by Oh \& Vanapalli (2011b, 2012) show that the SVS behaviour of shallow foundation in unsaturated soils can be reliably estimated when the FEA is carried out using the elastic modulus function (i.e. variation of elastic modulus with respect to the matric suction). This is because the FEA based on elastic - perfectly plastic model is mainly influenced by the elastic modulus and the Poisson's ratio, v. Oh \& Vanapalli (2012) investigated the influence of the Poisson's ratio on the SVS behavior of shallow foundation by conducting the FEA for different $v$ values. The estimated SVS behavior were relatively close to each other for the $v$ values used in the analysis (i.e. $v=0.1,0.2,0.3,0.4$ and 0.495). However, better comparison between the measured and the estimated SVS behaviour was obtained for the $v$ values of 0.2 and 0.3 , which are more reasonable for sands.

In the present study, more focused investigations are undertaken to study the influence of Poisson's ratio on the SVS behaviour of shallow foundations in unsaturated finegrained soils. The FEA are performed using the SIGMA/W (GeoStudio 2007) for the model footing tests results (Oh \& Vanapalli 2013b) in UFG soils. The elastic - perfectly plastic model was used for the FEA and the SVS behavior estimated taking account of the influence of suction with different values of Poisson's ratio are compared with those from the model footing tests. Based on the results of these studies several suggestions are made with respect to the influence of Poisson's ratio on the SVS behavior for shallow foundations in the UFG soils.

\section{Model Footing test in Unsaturated Fine-Grained Soil}

Oh \& Vanapalli (2013b) conducted a series of model footing tests on a statically compacted glacial till using specially designed equipment (Fig. 1). The tests were performed for five different average matric suction values (i.e. $0,55,100,160$, and $205 \mathrm{kPa}$ ). The value of matric suction at the center of gravity of the matric suction distribution diagram from 0 to $1.5 B$ ( $B=$ width of foundation) depth region was considered as the average matric suction. $1.5 B$ is the depth in which the stress below a shallow foundation is pre-

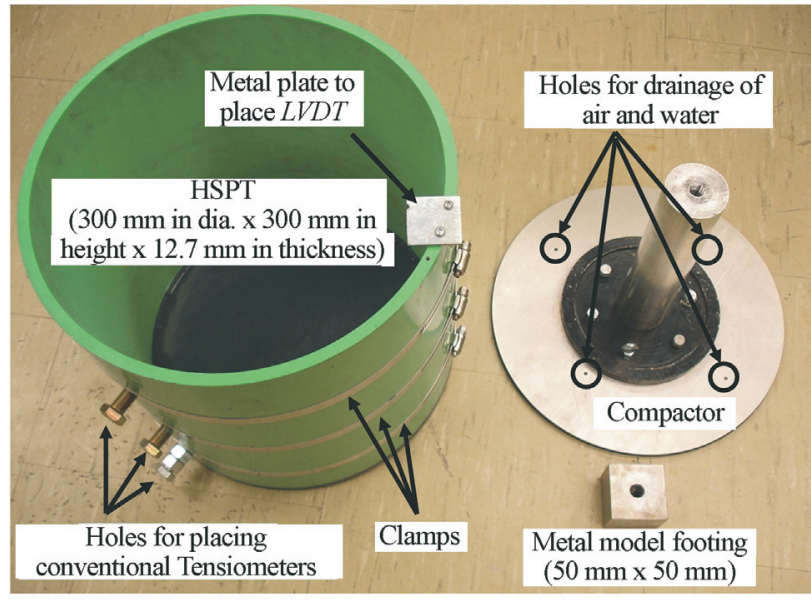

Figure 1 - Equipments used in the study for conducting model footing tests (Oh \& Vanapalli, 2013b).

dominant (Agarwal \& Rana 1987, Vanapalli \& Mohamed 2007, Oh et al., 2009, Oh \& Vanapalli 2011a,b). The matric suction distribution diagrams with depth for different average matric suction values were obtained based on the SWCC (Fig. 2) using water contents measured along with depth. The SWCC was measured using pressure plate technique. Figure 3 and Fig. 4 show the model footing test setup and the SVS behaviors for five different matric suction values. The bearing capacity values were determined using a graphical method (i.e. stress corresponding to the intersection of elastic and plastic line on the SVS behavior).

\section{Finite Element Analysis}

Oh \& Vanapalli (2011) suggested that the FEA can be effectively used to simulate the SVS behavior of shallow foundations on unsaturated soils using an elastic - perfectly plastic model with the Mohr-Coulomb yield criterion. In the present study, commercial FEA software, SIGMA/W (GeoStudio 2007) is used to simulate the SVS of the model

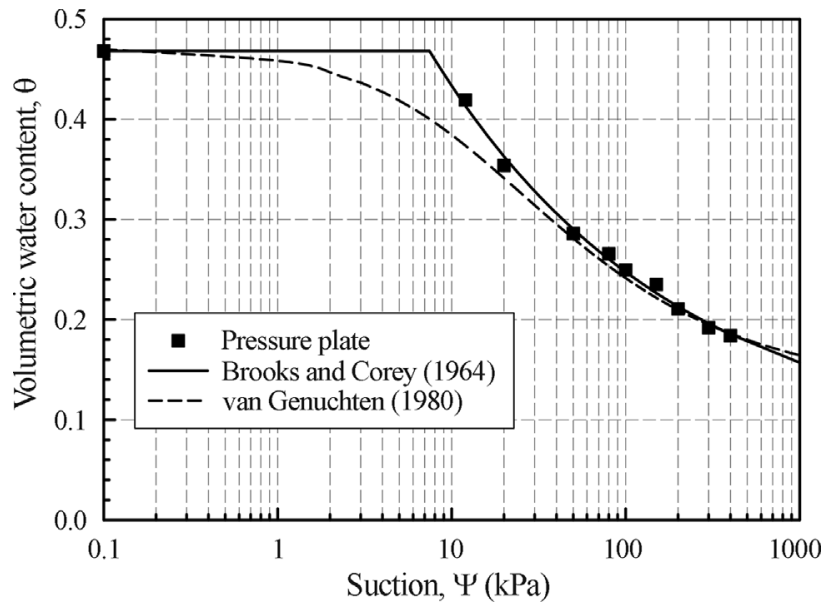

Figure 2 - Soil-water characteristic curve measured using pressure plate technique (modified after Oh \& Vanapalli, 2013b). 


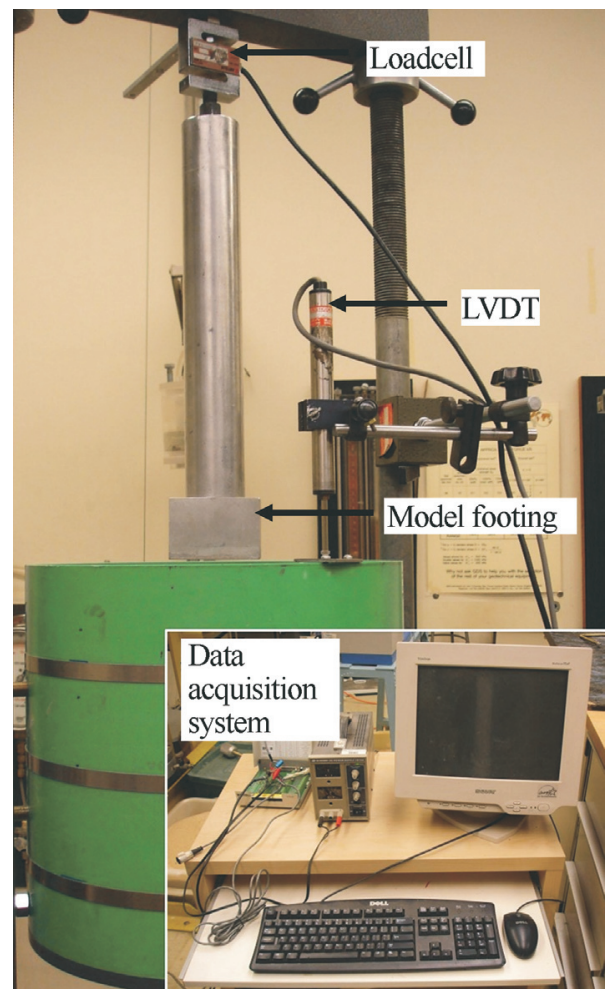

Figure 3 - Equipment set-up for conducting model footing tests (Oh \& Vanapalli, 2013b).

Applied stress, $\mathrm{q}(\mathrm{kPa})$

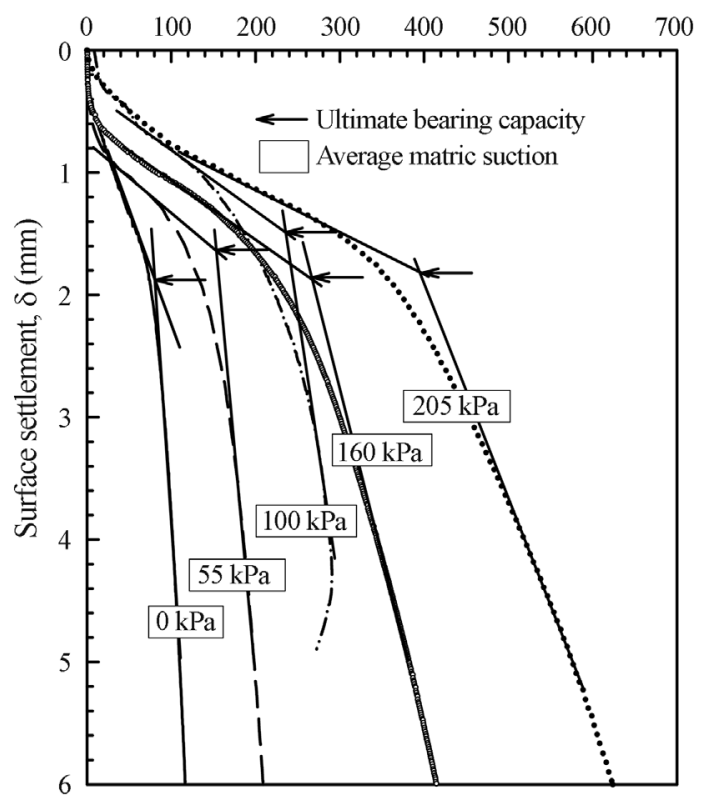

Figure 4 - Bearing capacity test results (modified after Oh \& Vanapalli, 2013b).

footing test results by Oh \& Vanapalli (2013b). The main input parameters required for the elastic - perfectly plastic model are cohesion and internal friction angle, initial tangent elastic modulus, and Poisson's ratio.

\subsection{Cohesion and internal friction angle}

Oh \& Vanapalli (2013b) suggested that the bearing capacity of unsaturated soils should be estimated considering soil type and drainage condition. Based on this concept, they proposed two approaches, Modified Effective Stress Approach (MESA) and Modified Total Stress Approach (MTSA) for unsaturated coarse- and fine-grained soils, respectively. In the case of unsaturated coarse-grained soils, (i) both the pore-air and the pore-water in soils are in drained condition during the loading stages and (ii) the general failure can be expected for relatively high density coarse-grained soils. In other words, the bearing capacity of unsaturated coarse-grained soils can be reliably estimated extending effective stress approach using effective shear strength parameters, $c^{\prime}$ and $\phi$ ' for saturated condition (i.e. MESA, Vanapalli \& Mohamed 2007).

$$
\begin{aligned}
& q_{\text {ult (unsat })}=\left[c^{\prime}+\left(u_{a}-u_{w}\right)_{b}\left(1-S^{\psi_{B C}} \tan \phi^{\prime}\right)+\right. \\
& \left.\left(u_{a}-u_{w}\right)_{A V R} S^{\psi_{B C}} \tan \phi^{\prime}\right] N_{c} \xi_{c}+0.5 B \gamma N_{\gamma} \xi_{\gamma}
\end{aligned}
$$

where $q_{\text {ultunsat })}=$ ultimate bearing capacity of unsaturated soils, $\left(u_{a}-u_{w}\right)_{b}=$ air-entry value, $\left(u_{a}-u_{w}\right)_{A V R}=$ average matric suction value, $S=$ degree of saturation, $\gamma=$ soil unit weight, $\psi_{B C}=$ fitting parameter with respect to bearing capacity ( $\psi_{B C}=1$ for coarse-grained soils), $B=$ width of footing, $N_{c}$, $N_{\gamma}=$ bearing capacity factor from Terzaghi (1943) and Kumbhokjar (1993), respectively, and $\xi_{c}=\left[1.0+\left(\frac{N_{q}}{N_{c}}\right)\left(\frac{B}{L}\right)\right], \xi_{\gamma}=\left[1.0-0.4\left(\frac{B}{L}\right)\right]=$ shape factors from Vesic (1973).

In SIGMA/W (2007), the influence of matric suction on the cohesion is considered using Eq. 2 (Vanapalli et al., 1996). A constant value of effective internal friction angle, $\phi '$ can be used in the FEA as $\phi$ ' is not influenced by matric suction (Vanapalli et al., 1996, Wang et al., 2002, Nishimura et al., 2007).

$$
c=c^{\prime}+\left(u_{a}-u_{w}\right)\left[\left(\frac{\theta_{w}-\theta_{r}}{\theta_{s}-\theta_{r}}\right) \tan \phi^{\prime}\right]
$$

where $\mathrm{c}=$ total cohesion, $c^{\prime}, \phi^{\prime}=$ effective cohesion and internal friction angle, respectively, $\left(u_{a}-u_{w}\right)=$ matric suction, $\theta_{w}=$ volumetric water content, $\theta_{s}=$ saturated volumetric water content, and $\theta_{r}=$ residual volumetric water content

On the other hand, the behavior of the UFG soils below footings can be interpreted using the punching shear failure mechanism (Oloo 1994, Schnaid et al., 1995, Consoli et al., 1998, Costa et al., 2003, Rojas et al., 2007). For punching shear failure condition, the slip surfaces below footings are typically not extended to the ground surface but instead restricted to vertical planes and no heave is observed on the surface of the soil as shown in Fig. 5. This characteristic behaviour indicates that the bearing capacity 
of the UFG soils is governed by the compressibility of the soil below a footing (i.e. soil A-A'-B-B' in Fig. 5; hereafter referred to as soil block). When the soil block, A-A'-B-B' is compressed due to the stress applied by a footing the soil around the soil block acts as confining pressure. In other words, the bearing capacity of the UFG soils can be represented as a function of a compressive strength of the soil block. A reasonable assumption can be made with respect to the pore-air to be under drained condition while the pore-water is under undrained condition during the loading stages of model footings or in-situ plate load tests in the UFG soils. This means that the pore-air is equal to atmospheric pressure and the water content in the soil is constant throughout the loading stage. Among the various methods available for estimating the shear strength of unsaturated soils, the constant water content (CW) test is regarded as the most reasonable technique for simulating this loading and drainage condition (Rahardjo et al., 2004; Infante Sedano et al., 2007). The CW test is however time-consuming and needs elaborate testing equipments. Hence, the unconfined compressive shear strength for unsaturated finegrained soils can be used instead of the conventional $\mathrm{CW}$ test results. The use of unconfined compression test results can be justified based on the following facts and reasonable assumptions.

(i) The drainage condition in unconfined compression tests for unsaturated fine-grained soils is the same as the $\mathrm{CW}$ test (i.e. pore-air pressure is atmospheric pressure and the water content is constant throughout the test).

(ii) The shear strength increases with increasing confining pressure for the same matric suction values for $\mathrm{CW}$ test (Rahardjo et al., 2004). Therefore, the shear strength obtained from the unconfined compression tests typically provides conservative estimates.

Based on this discussion, Oh \& Vanapalli (2013b) suggested that the bearing capacity of UFG soils can be estimated using Eq. 3 extending the total stress approach (i.e. MTSA).

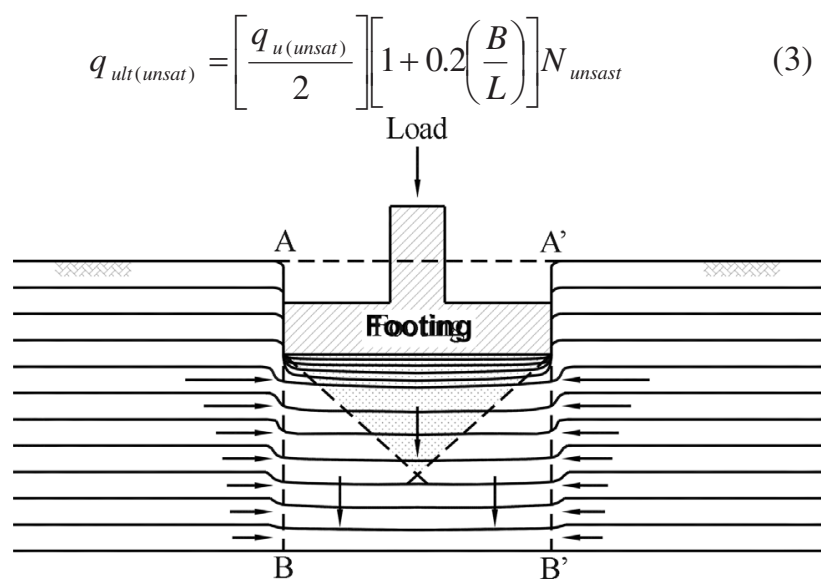

Figure 5 - Punching shear failure mechanism in unsaturated finegrained soils below a footing (modified after Oh \& Vanapalli, 2013b). where $q_{\text {ultusaut }}=$ ultimate bearing capacity of unsaturated fine-grained soil, $q_{u(\text { unsat }}=$ unconfined compressive strength for unsaturated fine-grained soil, $B, L=$ width and length of foundation, and $N_{\text {ursat }}=$ bearing capacity factor $N_{c}$ for the UFG soil.

\subsection{Initial tangent elastic modulus}

The initial tangent elastic modulus, $E_{i}$ from plate load (or model footing) test can be calculated using Eq. 4 (Fig. 6).

$$
E_{i}=\frac{\left(1-v^{2}\right)}{\left(\frac{\Delta \delta}{\Delta q}\right)} I_{w} B=k_{i s}\left(1-v^{2}\right) I_{w} B
$$

where $E_{i}=$ initial tangent elastic modulus, $v=$ Poisson's ratio (i.e. $v=0.3$ for coarse-grained soils), $\Delta q, \Delta \delta=$ applied stress and displacement in elastic range, respectively, $k_{i s}=$ initial tangent subgrade reaction modulus $(=\Delta \delta / \Delta q)$, $B=$ width of footing, and $I_{w}=$ influence factor (i.e. 0.88 for square plate)

In the case of FEA, the influence of $v$ on the SVS behavior is included as an input parameter. In addition, if the analysis is conducted as axisymmetric condition the influence of $I_{w}$ on the SVS behavior can be considered by using equivalent area. Hence, Oh \& Vanapalli (2011a) proposed the Eq. 5 to calcuated the $E_{i}$ for the FEA.

$$
E_{i}=\frac{1.5 B}{\left(\frac{\Delta \delta}{\Delta q}\right)}=\frac{\Delta q}{\left(\frac{\Delta \delta}{1.5 B}\right)}
$$

\subsection{Poisson's ratio}

The elastic $(E)$ and shear $(G)$ modulus of soils are two key parameters that are required in the evaluation of the immediate settlement and dynamic response behavior respectively of geotechnical structures in engineering practice. If

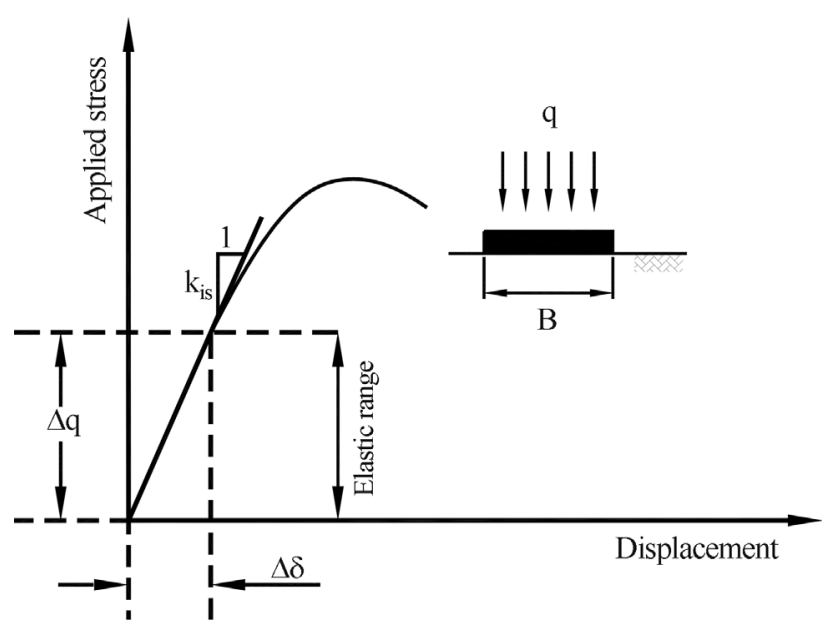

Figure 6 - Typical stress vs. settlement behavior from plate load test (Oh \& Vanapalli, 2011). 
a soil is assumed to be homogeneous, isotropic and linear elastic continuum the Poisson's ratio can be calculated using the relationship between the $E$ and the $G$. The Poisson's ratio, $v$ is typically assumed to be constant in the numerical modelling studies of both saturated and unsaturated soils. Such an assumption is reasonable for coarse-grained soils since the change in mean effective stress and associated volume change due to the wetting and drying cycles is negligible. However, in the case of fine-grained soils, the drying and wetting cycles contribute to significant volume changes in soils, which results in different compressibility characteristics with respect to the degree of saturation. In other words, the mathematical relationship between the $E$ and the $G$ that were originally developed for homogeneous, isotropic and linear elastic continuum may not applicable for the $E$ and the $G$ values for unsaturated soils.

The $E_{\max }-G_{\max }$, and $G_{\max }-M_{\max }$, and $M_{\max }-E_{\max }$ relationship for homogeneous, isotropic, and linear elastic continuum are given in Eqs. 6, 7, and 8, respectively.

$$
\begin{aligned}
E_{\max } & =2 G_{\max }(1+v) \\
G_{\max } & =\frac{(1-2 v)}{2(1-v)} M_{\text {max }} \\
M_{\max } & =\frac{(1-v)}{(1+v)(1-2 v)} E_{\max }
\end{aligned}
$$

where $E_{\max }=$ maximum elastic modulus, $G_{\max }=$ Maximum shear modulus and $M_{\max }=$ maximum constraint modulus (i.e. $E, G$ and $M$ at small strain)

Equation 6 and Eq. 7 can be extended to $E_{\max }, G_{\max }$, and $M_{\max }$ values measured for unsaturated soils as shown in Eq. 9 and Eq. 10, respectively.

$$
\begin{aligned}
& E_{\max (\text { unsat })}=2 G_{\max (\text { unsat })}(1+v) \\
& G_{\max }=\frac{(1-2 v)}{2(1-v)} M_{\max }
\end{aligned}
$$

where $E_{\max (\text { unsut })}, G_{\max (\text { unsat })}$, and $M_{\max (\text { ussat) }}=E_{\max }, G_{\max }$, and $M_{\max }$ for unsaturated condition, respectively

To check the validity of Eq. 9 and Eq. 10, Oh \& Vanapalli (2012) reanalyzed the $E_{\max (u n s a t)}, G_{\max (u n s a t)}$, and $M_{\text {max(unsat) }}$ values measured with the bender element test technique for different degree of saturation values (Mendoza $e t$ al., 2005, Alramahi et al., 2010).

Figure 7 shows the variation of back-calculated $v$ with respect to degree of saturation for the data by Mendoza et al. (2005). The negative $v$ and greater than 0.5 values were ignored since they are not realistic. A trend line is drawn assuming $v=0.1$ representing the relatively dry condition, which was also supported by Lee \& Santamarina (2005). In the case of bender element test results by Mendoza et al. (2005), the Poisson's ratio values are relatively high with the values between 0.5 and 0.35 in the boundary effect zone, which indicates that the soil specimens were close to undrained condition. The Poisson's ratio values in
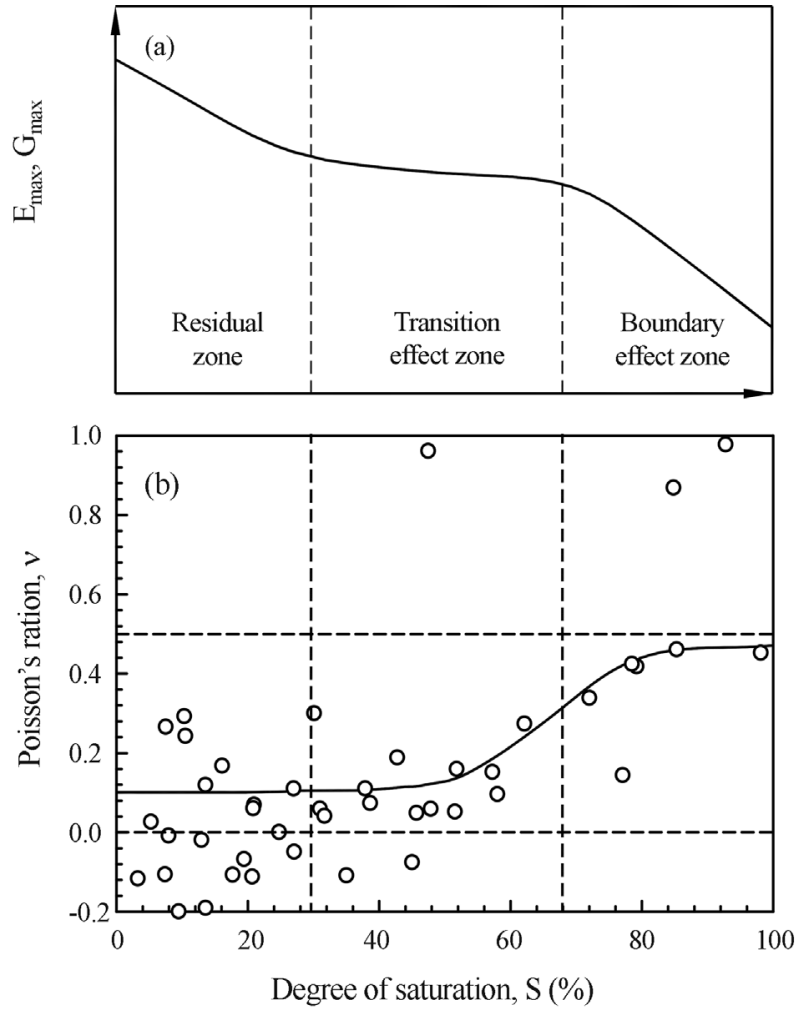

Figure 7 - a) Degree of saturation versus maximum elastic and shear modulus relationship and (b) back-calculated Poisson's ratio with respect to degree of saturation (data from Mendoza et al., 2005) (Oh \& Vanapalli, 2012).

the range of 0.35 and 0.1 typically fall in the transition effect zone. In residual zone, the Poisson's ratio gradually converges to a relatively constant value of 0.1 .

Figure 8(a) and (b) show the variation of back-calculated $v$ values with respect to degree of saturation for clay-slurry pore and silt-slurry pore, respectively for the data provided by Alramahi et al. (2010). The behavior shown in Fig. 8(a) (i.e. clay-slurry pore) is similar to that shown in Fig. 7(b); however, this behavior is not observed for the silt-slurry pore specimen (i.e. Fig. 8(b)). The difference in the back-calculated $v$ values between the saturated (i.e. $S=100 \%$ ) and the dry (i.e. $S=0 \%$ ) conditions for clay specimen (Mendoza et al., 2005) and clay- and silt-slurry pore specimens (Alramahi et al., 2010) are found to be 0.4 , 0.04 , and 0.02 respectively. This fact indicates that the variation of Poisson's ratio with respect to degree of saturation is more predominant for finer soil materials.

The results in Fig. 7 and Fig. 8 indicates that the Poisson's ratio can be expressed as a function of degree of saturation (i.e. $f(S)$; Eq. 11 and Eq. 12). Figure 7 and Fig. 8(a) also show that the variation of Poisson's ratio with respect to degree of saturation is similar to that of SWCC. In other words, the SWCC can be used as a tool to estimate the variation of Poisson's ratio with respect to degree of saturation. 

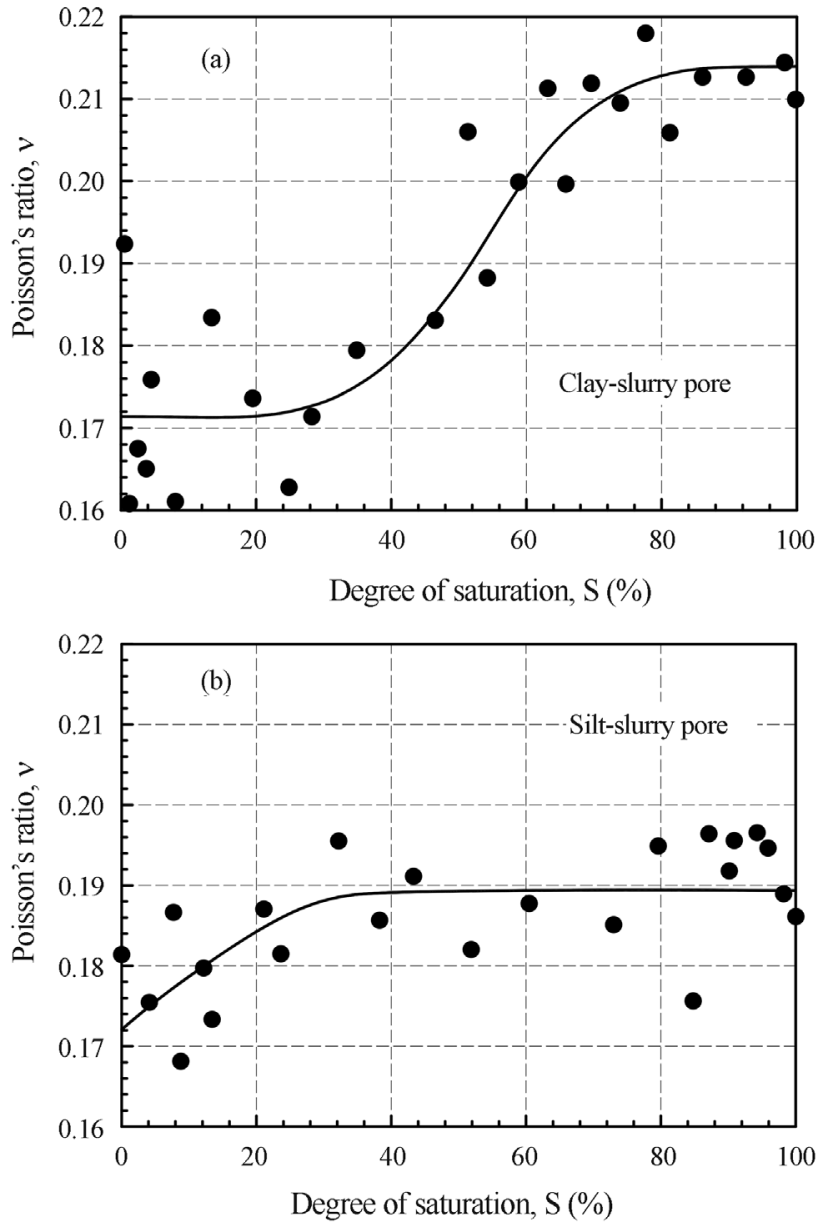

Figure 8 - Back-calculated Poisson's ratio with respect to degree of saturation for (a) clay-slurry pore and (b) silt-slurry pore (data from Alramahi et al., 2010) Oh \& Vanapalli, 2012).

$$
\begin{aligned}
& \mathrm{v}^{*}=\left[\frac{E_{\max (\text { unsat })}}{2 G_{\max (\text { unsat })}}\right]-1=f(S) \\
& \mathrm{v}^{*}=\left[\frac{M_{\max (\text { unsat })}-2 G_{\max (\text { unsat })}}{2\left(M_{\max (\text { unsat })}-G_{\max (\text { unsat })}\right)}\right]=f(S)
\end{aligned}
$$

where $v^{*}=$ Poisson's ratio of unsaturated soils, which is a function of degree of saturation

\section{Analysis Results}

\subsection{Soil properties boundary conditions used in the FEA}

In the present study, the model footing test results in UFG soils as detailed in Section 2 are used. Hence, the FEA for each average matric suction value was carried out using the half unconfined compressive strength as total cohesion for five different $v$ values (i.e. 0.1, 0.2, 0.3, 0.4, and 0.495). Figure 9 shows meshes along with boundary conditions used in the analysis. Model footing was considered as a material with extremely high elastic modulus and shear

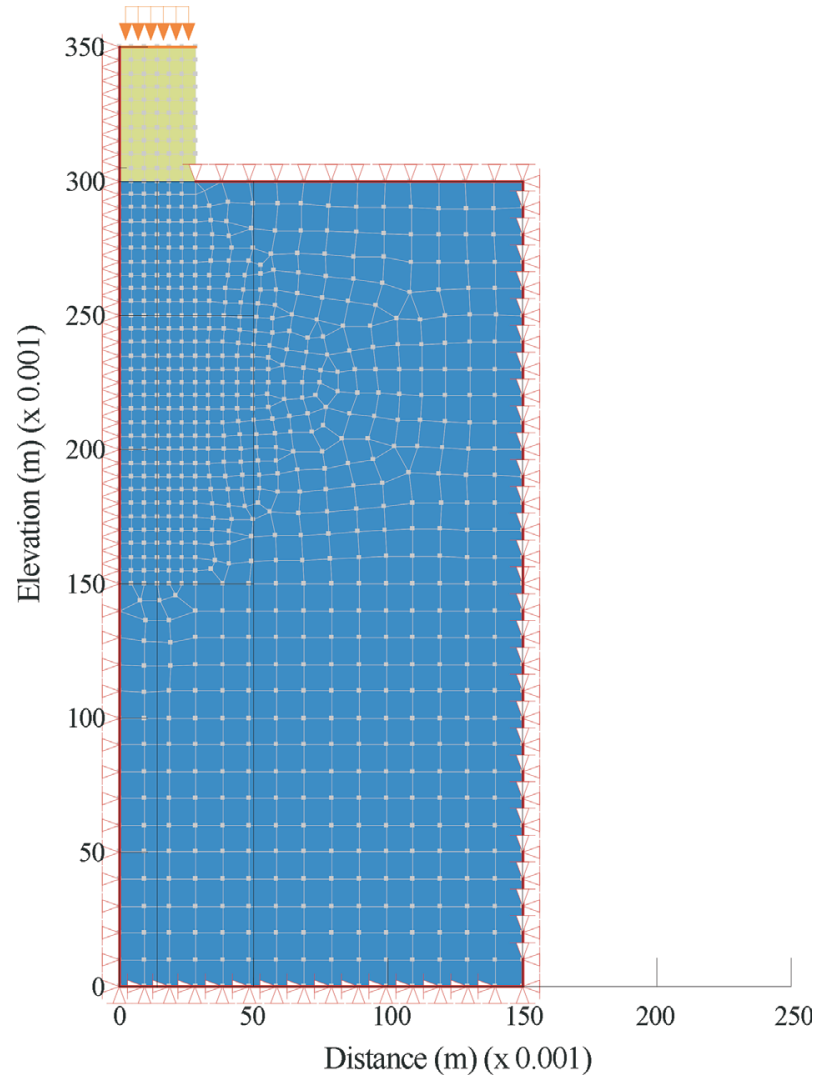

Figure 9 - Meshes and boundary condition used in the FEA.

strength parameters in the FEA. Analyses were performed as axisymmetric condition. The ' $y$-displacement fixed' boundary was assigned on the surface of the compacted soils to simulate "no heave (i.e. punching failure mechanism' as discussed in Section 3) condition.

\subsection{Comparison between the measured and estimated stress vs. settlement behaviors}

Figure 10 shows the comparisons between the measured SVS behaviors and those estimated using the FEA for five different Poisson's ratio values. Reasonable comparisons were observed between the measured and the estimated SVS behaviors regardless of Poison's ratio; however, best comparisons were achieved for low Poison's ratio values (i.e. less than 0.3). This good comparison also indicates that the MTSA can be successfully extended to the simulation of the SVS behavior of shallow foundations in UFG soils.

\section{Summary and Conclusions}

In the present study, the influence of Poisson's ratio on the stress vs. settlement (SVS) behavior of a model footing in an unsaturated fine-grained (UFG) soil is investigated. The conclusions obtained from the research can be summarized as below. 

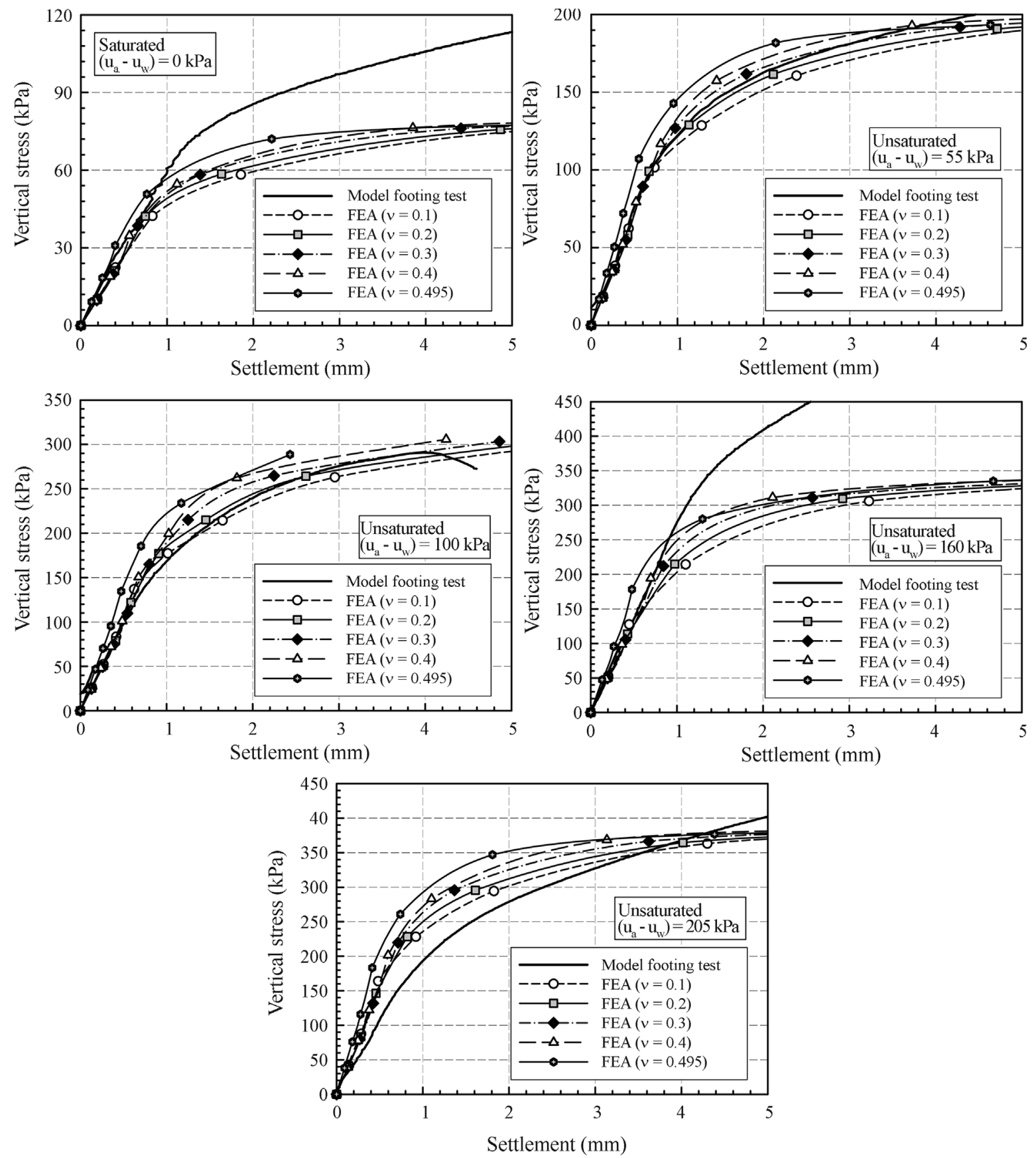

Figure 10 - Comparison between measured SVS behaviors and those estimated using the FEA for different Poisson's ratio.

1. The stress $v s$. settlement behavior of a model footing can be reliably estimated using the Finite Element Analysis (FEA) extending Modified Total Stress Approach (MTSA).

2. There was good comparison between the measured SVS behaviors and those estimated using the FEA with the Poisson's ratio values in the range of 0.1 and 0.3 .

3. Poisson's ratio is not constant, but varies with respect to degree of saturation. In other words, there is a strong relationship between Poisson's ratio and the SWCC. Hence, it is necessary to conduct more studies on vari- ous types of unsaturated soils (including expansive soils) to develop a semi-empirical model to estimate the variation of Poisson's ratio with respect to degree of saturation using SWCC.

\section{References}

Adem, H.H. \& Vanapalli, S.K. (2013). Constitutive modeling approach for estimating the $1-D$ heave with respect to time for expansive soils. International Journal of Geotechnical Engineering, 7(2):199-204. 
Agarwal, K.B. \& Rana, M.K. (1987). Effect of ground water on settlement of footing in sand. Proc. 9th European Conference on Soil Mechanics and Foundation Engineering, Dublin, pp. 751-754.

Alramahi, B.; Alshibli, K.A. \& Fratta, D. (2010). Effect of fine particle migration on the small-strain stiffness of unsaturated soils. Journal of Geotechnical and Geoenvironmental Engineering, 136(4):620-628.

Ausilio, E. \& Conte, E. (1999). Settlement rate of foundations on unsaturated soils. Canadian Geotechnical Journal, 36(5):940-946.

Cerato, A.B. \& Lutenegger, A.J. (2006). Bearing capacity of square and circular footings on a finite layer of granular soil underlain by a rigid base. Journal of Geotechnical and Geoenvironmental Engineering, 132(11):1496-1501.

Chao, K.C.; Neslon, J.D. \& Overton, D.D. (2011). Factors influencing design of deep foundations on expansive soils. Proc. 5th Asia Pacific Conference on Unsaturated soils, Pattaya, Thailand, v. 2, pp. 829-834.

Chen, W.F. \& Zhang, H. (1991). Structural plasticity: Theory, problems, and CAE software. Springer-Verlag.

Consoli, N.C.; Schnaid, F. \& Milititsky, J. (1998). Interpretation of plate load tests on residual soil site. Journal of Geotechnical and Geoenvironmental Engineering, 124(9):857-867.

Costa, Y.D.; Cintra, J.C. \& Zornberg J.C. (2003). Influence of matric suction on the results of plate load tests performed on a lateritic soil deposit. Geotechnical Testing journal, 26(2):219-226.

Gallipoli, T.; Sanchez, M. \& Sheeler, S. (2013). Rainfall-induced differential settlements of foundations on heterogeneous unsaturated soils. Géotechnique, 63(15):1346-1355.

Georgiadis, K.; Potts, D.M. \& Zdravkovic, L. (2003). The influence of partial soil saturation pile behaviour. Géotechnique, 53(1):11-25.

Infante Sedano, J.A.; Vanapalli, S.K. \& Garga, V.K. (2007). Modified ring shear apparatus for unsaturated soils testing. Geotechnical Testing Journal, 30(1):1-12.

Kumbhokjar, A.S. (1993). Numerical evaluation of Terzaghi's N $\gamma$. Journal of Geotechnical Engineering, ASCE, 119(3):598-607.

Lee, J-S \& Santamarina, J.C. (2005). Bender elements: Performance and signal interpretation. Journal of Geotechnical and Geoenvironmental Engineering, 131(9):1063-1070.

Mendoza, C.E.; Colmenares, J.E. \& Merchán, V.E. (2005). Stiffness of an unsaturated compacted clayey soil at very small strains. Proc. of Int. Symp. on Advanced Experimental Unsaturated Soil Mechanics, Ternto, pp. 199-204.

Mohamed, F.M.O. \& Vanapalli, S.K. (2006). Laboratory investigations for the measurement of the bearing capacity of an unsaturated coarse-grained soil. Proc. 59th
Canadian Geotechnical Conference, Vancouver, pp. 219-226.

Nishimura, T.; Toyota, H.; Vanapalli, S.K. \& Oh, W.T. (2007). Evaluation of critical state parameters for an unsaturated soil. Proc. 60th Canadian Geotechnical conference, Ottawa, Ontario, pp. 1029-1036.

Oh, W.T.; Vanapalli, S.K. \& Puppala, A.J. (2009). Semiempirical model for the prediction of modulus of elasticity for unsaturated soils. Canadian Geotechnical Journal, 48(6):903-914.

Oh, W.T. \& Vanapalli, S.K. (2011a). Modelling the applied vertical stress and settlement relationship of shallow foundations in saturated and unsaturated sans. Canadian Geotechnical Journal, 48(3):425-438.

Oh, W.T. \& Vanapalli, S.K. (2011b). Modelling the stress $v s$. displacement behavior of shallow foundations in unsaturated coarse-grained soils. Proc. 5th Int. Symp. on Deformation Characteristics of Geomaterials, Seoul, South Korea, pp. 821-828.

Oh, W.T. \& Vanapalli, S.K. (2012). Modelling the settlement behaviour of in-situ shallow foundations in unsaturated sands. Proc. Geo-Congress 2012, ASCE, pp. 2542-2551.

Oh, W.T. \& Vanapalli, S.K. (2013a). Scale effect of plate load tests in unsaturated soils. International Journal of Geomate, 4(2):585-594.

Oh, W.T \& Vanapalli, S.K. (2013b). Interpreting the bearing capacity of unsaturated fine-grained soils using modified effective and total stress approaches. International Journal of Geomechanics. (Accepted for publication)

Oloo, S.Y.; Fredlund, D.G. \& Gan, J.K-M. (1997). Bearing capacity of unpaved roads. Canadian Geotechnical Journal, 34(3):398-407.

Rahardjo, H.; Heng, O.B. \& Leong, E.C. (2004). Shear strength of a compacted residual soil from consolidated drained and the constant water content tests. Canadian Geotechnical Journal, 41(3):1-16.

Rojas, J.C.; Salinas, L.M. \& Seja, C. (2007). Plate-load tests on an unsaturated lean clay. Proc. 2nd Int. Conf. on Unsaturated Soils, Weimar, pp. 445-452.

Schnaid, F.; Consoli, N.C.; Cumdani, R. \& Milititsky, J. (1995). Load-settlement response of shallow foundations in structured unsaturated soils. Proc. 1st Int. Conf. on Unsaturated Soils, Paris, pp. 999-1004.

Terzaghi, K. (1943). Theoretical Soil Mechanics. John Wiley and Sons, New York, 510 p.

Vanapalli, S.K.; Fredlund, D.G.; Pufahl, D.E. \& Clifton, A.W. (1996). Model for the prediction of shear strength with respect to soil suction. Canadian Geotechnical Journal, 33(3):379-392.

Vanapalli, S.K. \& Mohamed, F.M.O. (2007). Bearing capacity of model footings in unsaturated soils. Proc. Int. Conf. From Experimental Evidence towards Numerical 
Modeling of Unsaturated Soil, Weimar, Germany, pp. 483-493.

Vanapalli, S.K. \& Oh, W.T. (2009). A model for predicting the modulus of elasticity of unsaturated soils using the soil-water characteristic curves. International Journal of Geotechnical Engineering, 4(4):425-433.

Vanapalli, S.K. \& Taylan, Z.N. (2012). Design of single pile foundations using the mechanics of unsaturated soils. International Journal of Geomate, Construction Materials and Environment, 2(1):197-204.

Vesic A.B. (1973). Analysis of ultimate loads of shallow foundations. Journal of the Soil Mechanics and Foundation Division, ASCE 99(1):45-73.
Vu, H.Q. \& Fredlund, D.G. (2006). Challenges to modelling heave in expansive soils. Canadian Geotechnical Journal, 43:1249-1272.

Wang, Q.; Pufahl, D.E. \& Fredlund, D.G. (2002). A study of critical state on an unsaturated silty soil. Canadian Geotechnical Journal, 39(1):213-218.

Weaver, T. \& Grandi, O. (2009). Lateral load analysis of deep foundations in unsaturated soils. contemporary topics in in situ testing, analysis, and reliability of foundations. Geotechnical Special Publications, 186:552559.

Wejrungsikul, T.; Puppala, A.J.; Williammee, R.S.; Ruttanaporamakul, Jr. P. \& Hoyos, L.R. (2011). Inclined load capacities of drilled shafts in unsaturated soil environments. Proc. 5th Asia Pacific Conference on Unsaturated soils, Pattaya, Thailand, v. 2, pp. 817-822. 